\title{
Can Chrono-Nutrition Help Prevent Diabetes?
}

\author{
Akbar Nikkhah, \\ Chief Highly Distinguished Professor and Scientist Ferdows Pars Holding Co., Tehran, Iran
}

Corresponding Author: Akbar Nikkhah, Chief Highly Distinguished Professor and Scientist Ferdows Pars Holding Co., Tehran, Iran.

Received Date: 15 December 2021 | Accepted Date: 03 January 2022 | Published Date: 11 January 2022

Citation: Akbar Nikkhah, (2022). Can Chrono-Nutrition Help Prevent Diabetes? J. Diabetes and Islet Biology, 5(1); DOI:10.31579/2641-8975/031

Copyright: (C) 2022 Akbar Nikkhah, This is an open access article distributed under the Creative Commons Attribution License, which permits unrestricted use, distribution, and reproduction in any medium, provided the original work is properly cited.

\begin{abstract}
This editorial aimed to put forward a question if chrono-nutrition can help prevent diabetes through optimizing circadian rhythms of glucose metabolism. With the advancing mechanization, eating behavior (timing, sequence, and frequency) has changed. People are now more willing to eat fast foods at suboptimal times of the circadian period. Growing evidence suggests that untimely eating and lack of exercise can interfere with optimal physiological rhythms of glucose and insulin metabolism that can lead to diabetes. Type 2 diabetes mellitus (T2D) is a foremost metabolic disorder worldwide occurring largely due to suboptimal eating timing and lifestyle. Consuming less sugars and carbohydrates during evening and overnight may help optimize human chronophysiology. Chrono-nutrition via optimizing the timing of meals is a growing science that needs to be well practiced to help prevent or possibly reduce risks of T2D in today's complicated life.
\end{abstract}

Key words: chrono-nutrition; circadian rhythm; glucose; diabetes; physiology; science

\section{Philosophy}

This objective of this editorial was to develop and address a question if chrono-nutrition can help prevent diabetes through optimizing circadian rhythms of glucose metabolism. The suprachiasmatic nucleus (SCN) is a structure present in the hypothalamus and a central clock that alongside peripheral clocks in liver orchestrates circadian rhythms of glucose metabolism [1,2]. It is known that glucose tolerance decreases in the evening and night simply and philosophically because less nutrients are needed overnight [3]. As such, eating large evening meals of mainly highsugar and starchy foods should be avoided to reduce risk of T2D. Contemplation in the circadian rhythms of glucose metabolism suggests decreased insulin sensitivity and pancreatic $\beta$-cells function in the evening vs. morning [2]. Increased insulin resistance is a predisposing factor for T2D development [4]. Moreover, insulin resistance and energy overintake leads to hepatic and abdominal adiposity, likely increasing hepatic insulin resistance and suboptimal hepatic and peripheral glucose metabolism [4]. Subsequently, glucose over-flux during evening and overnight increases the risk of insulin resistance that could increase T2D likelihood [5].

Glucose metabolism is meticulously associated with circadian systems. Thus, changing the main eating time from morning to evening might cause elevated blood glucose and its related problems. The evening chronotype people tend to consume foods heavily late overnight. It has been shown that night workers have reduced glucose tolerance, and thus, are at higher risks of prediabetes and diabetes development. This suggests abnormal circadian metabolism of glucose in shift workers and nocturnal eaters [6].
Moreover, increased melatonin secretion has been reported in late eaters, suggesting impaired glucose metabolism and disturbed glucose circadian rhythms [2]. Melatonin is known for its basic role in sleep-cycle and circadian rhythms regulation. Increased melatonin secretion overnight coincided with heavy evening food intake may further impair glucose metabolism towards lower glucose tolerance [7]. Hence, the increased diabetes risk in nocturnal eaters and shift-workers might be because of the disrupted circadian rhythms of glucose metabolism. In addition, melatonin possesses an inhibitory effect on insulin secretion that further complicates the problem [7].

From a meal timing perspective, then, chrono-nutrition implies that highenergy nutrients should be consumed rather early in the morning when physical activity and brain work increase [5]. As such, consuming breakfast is encouraged, but nocturnal eating is discouraged [8]. Besides eating timing, improved nutrient and waste metabolism will depend on well-coordinated eating and exercise that requires future research. Overall, chrono-nutrition is an emerging science that can offer a simple and feasible methodology to help optimize glucose metabolism and reduce diabetes risk.

\section{Implication}

Glucose metabolism is orchestrated through circadian rhythms. Glucose tolerance, for instance, decreases during evening and overnight. Thus, night eaters may exhibit elevated blood glucose or hyperglycemia nocturnally. The increased hyperglycemia together with the greater insulin resistance are the predisposing factors for T2D. It is suggested that chrono-nutrition is a growing science and practice that comes to play an 
important role in preventing diabetes through optimizing glucose metabolism circadian rhythmicity in today's stressful life.

\section{Acknowledgement}

Nature and Mountains are acknowledged for their inspirations in scientific contemplations.

\section{References}

1. Nikkhah A. Avoid large night meal to stay fit. Journal of Obesity \& Weight Loss Therapy (2014); 4: e115

2. Mason CI, Qian J, Alder KG and Scheer AJL Frank. Impact of circadian disruption on glucose metabolism: implication for type 2 diabetes. Diabetologia (2020); 63: 462-472.

3. Nikkhah A. Human chronophysiology and chrono-nutrition: Emerging sciences. Journal of Acta Scientific Nutritional Health (2019); 3: 104-105.
4. Florinela Catoi A, Parvu A, Muresan A and Busetto L. Metabolic Mechanisms in obesity and type 2 diabetes: insights from bariatric/metabolic surgery. Obes Facts (2015); 8: 350363.

5. Nikkhah A. Safety against diabetes via optimizing intake patterns: Science evolution cropped. Advances in Crop Science and Technology (2015); S1: e001.

6. Christiani HJ, Bhupinder K, and Rina YCQ. Chrononutrition in the management of diabetes. Nutrition and Diabetes (2020); 10:6.

7. Garaulet M, Qian J, Florez JC, Aredt J, Saxena R, and Scheer Frank AJL. Melatonin effects on glucose metabolism: Time to unlock the controversy. Trends in Endocrinology metabolism (2020); 31: 192-204.

8. Nikkhah A. Discovering the right time to take food to smash diabetes. Journal of Diabetes Research and Therapy (2015); $1: 1$.
This work is licensed under Creative Commons Attribution 4.0 License
Ready to submit your research? Choose Auctores and benefit from:

$>$ fast, convenient online submission

$>$ rigorous peer review by experienced research in your field

$>$ rapid publication on acceptance

$>$ authors retain copyrights

$>$ unique DOI for all articles

$>$ immediate, unrestricted online access

At Auctores, research is always in progress.

Learn more https://auctoresonline.org/journals/diabetes-and-islet-biology- 